\title{
In Vitro Studies of Human Ragweed Allergy: Changes in Cellular and Humoral Activity Associated with Specific Desensitization*
}

\author{
Lawrence M. Lichtenstein, $\dagger$ Philip S. Norman $\ddagger$ Walter L. Winken- \\ Werder, and Abraham G. Osler $\S$ \\ (From the Departments of Medicine and Microbiology, the Johns Hopkins University \\ School of Medicine, Baltimore, $M d$.)
}

Specific hay fever therapy has long been based on the inoculation of pollen extracts, a regimen whose efficacy is not definitely established and whose mode of action is poorly understood (1). At the clinical level, injection of the culpable antigens in subreactive amounts is often followed by symptomatic improvement and diminished allergic responses of the mucous membranes and skin (1-4). Immunologically, these changes coincide with an increased production of blocking and hemagglutinating antibodies and, probably, with a diminution in the skin-sensitizing capacity of the serum (5-8). Despite these findings, efforts to establish a causal relationship between the parenteral injection of antigen, the immune response, and symptomatic relief have met with considerable difficulty $(9,10)$. The major problems have been the lack of accurate and valid procedures for assessing the degree of sensitivity to the pollen antigens and for characterizing the patient's immune response in terms of his clinical status.

Recent reports from this laboratory have outlined in vitro procedures for studying the release

\footnotetext{
* Submitted for publication January 14, 1966; accepted March 22, 1966.

Supported by grants AI- 05780 and AI-04866 from the National Institute of Allergy and Infectious Diseases.

$\dagger$ Address requests for reprints to Dr. Lawrence M. Lichtenstein, Dept. of Medicine, Johns Hopkins University School of Medicine, 601 N. Broadway, Baltimore, Md. 21205.

$¥$ Research Career Development Awardee, National Institute of Allergy and Infectious Diseases.

$\S$ This investigation has also been supported in part by the National Science Foundation, grant G-6205; the American Cancer Society, Inc., grant T-257B; the National Institute of Allergy and Infectious Diseases, grant AI-03151-06; and the Office of the Surgeon General, Department of the Army, under the auspices of the Commission on Immunization of the Armed Forces Epidemiological Board, contract DA-49-193-MD-2468.
}

of histamine from human leukocytes by ragweed pollen antigen (11-14). These procedures appear suitable for the study of human allergic disease in that they mimic the in vivo situation and permit a quantitative evaluation of several facets of the allergic response, namely: 1 ) the capacity of leukocytes from a ragweed-sensitive donor to release histamine on interaction with physiologically active quantities of a purified pollen antigen (11, $12)$; and 2) the ability of serum from an allergic donor to react with antigen in the fluid phase, thereby diminishing the anaphylactic release of histamine from the leukocytes $(13,14)$.

These two procedures have now been applied to a combined clinical and laboratory undertaking designed to evaluate the effects of parenteral immunization on the course of human ragweed allergy. VanArsdel and Middleton have previously demonstrated a decrease in histamine release from the whole blood of patients undergoing specific hyposensitization (15) [see also Spain, Strauss, and Neumann (16)]. In the present study a washed suspension of leukocytes has been used, rather than whole blood, to permit an independent evaluation of both humoral and cellular factors. Furthermore, the development of a more accurate system for assessing patient symptomatology (17) and the availability of a single highly purified antigen from ragweed pollen $(18,19)$ have significantly facilitated comparisons of laboratory and clinical observations.

\section{Methods}

Selection of patients. The patients selected for this study were drawn from a larger group undergoing a therapeutic trial designed to compare the clinical efficacy of crude ragweed pollen extract with its highly purified derivative, antigen $\mathrm{E}$, and a saline placebo. Each subject presented a history of hay fever symptoms restricted, 
with few exceptions, to the season of ragweed pollination. The leukocytes of 56 patients were assayed for their ability to release histamine on contact with antigen. Forty-one responded adequately. The remaining 15 were rejected for the following reasons: In two cases, histamine was not released at the antigen level tested. The leukocytes of five subjects released less than $50 \%$ of their available histamine, and in five other cases untowardly high blanks were observed when the cells were incubated with serum from nonallergic donors in the absence of antigen (cf. 13). In three cases the leukocyte histamine levels were too low for assay.

The 41 patients were divided into three groups. Eleven subjects had received antigen $E$ previously, and this therapy was continued. The remaining 30 patients were randomly divided between the placebo and crude ragweed treatment groups. For various technical reasons a complete set of data was not obtained from all donors.

Desensitization treatment. The crude ragweed extract was obtained in concentrated form ${ }^{1}$ and contained 10,000 protein nitrogen units $(100 \mu \mathrm{g}$ protein $\mathrm{N})$ per $\mathrm{ml}$. The antigen $\mathrm{E}$ content of this material was $38 \mu \mathrm{g}$ per $\mathrm{ml}$ (20). Antigen $\mathrm{E}$ was furnished as Fraction IV $\mathrm{C}$ by Dr. T. P. King, who reported that $99 \%$ of this material was antigen $E(18,19)$. Antigen $E$ is $17.1 \pm 0.3 \%$ nitrogen by analysis (19). All patients received 15 injections at weekly intervals from May 6 to August 12, 1964. The physician administering the injections was aware of the individual's therapeutic regimen, but the patient was not informed of the nature of the injected material. The first injection consisted of $0.002 \mu \mathrm{g}$ $(0.0003 \mu \mathrm{g}$ protein $\mathrm{N})$ for the patients treated with antigen $\mathrm{E}$ and $0.001 \mu \mathrm{g}$ protein $\mathrm{N}$ for the patients treated with whole ragweed extract. These doses were doubled each week provided the previous injection had produced no reaction. When a reaction did occur, the dose was maintained at the previous level; the quantity was reduced after severe reactions. Of the 15 patients receiving whole ragweed extract, only two completed the projected course of doubling doses for 15 injections. In the others, dosage was limited by local pain, itching, and swelling at the site of injection. Four patients showed mild to moderate systemic reactions in the form of hives. The total preseasonal dose for this group ranged from 0.39 to $28.8 \mu \mathrm{g}$ protein $\mathrm{N}$, containing 0.15 to $11 \mu \mathrm{g}$ antigen $\mathrm{E}(0.026$ to $1.84 \mu \mathrm{g}$ protein $\mathrm{N})$. Of the ten patients receiving antigen $\mathrm{E}$, five completed the projected course; one of these received an additional injection inadvertently. In four of the patients who did not complete the projected course, the dosage was limited by local reactions, mostly of the immediate wheal and erythema type. The fifth patient had a mild systemic reaction. The total preseasonal dose in the group treated with antigen $\mathrm{E}$ ranged from 4.0 to $61.7 \mu \mathrm{g}$ ( 0.7 to $11.2 \mu \mathrm{g}$ protein $\mathrm{N})$.

Evaluation of hay fever symptoms. A daily symptom diary card ${ }^{2}$ was kept by each patient from August 12 to

\footnotetext{
1 Greer Drug and Chemical Co., Lenoir, N. C.

2 The diary card was similar to that developed by Dr. Marie B. Rhyne of the Johns Hopkins University School of Medicine.
}

September 27, 1964. Each patient was requested to evaluate his symptoms for the previous 12 hours at noon and again at bedtime. Separate ratings were given for 1) sneezing, 2) stuffy, runny nose, 3) red, itchy eyes, and 4) coughing. Each symptom was scored as no symptoms (0), symptoms for less than 30 minutes (1), 30 minutes to 2 hours (2), or more than 2 hours (3). Antihistamine tablets (dexchlorpheniramine maleate, $2 \mathrm{mg}$ ) ${ }^{3}$ were furnished to each patient, and the number of tablets taken daily was added to the symptom score. The numerical scores were totaled to derive a daily symptom score for each patient day. Analysis of the results showed that the interpretation of the group average data was the same whether the use of antihistaminics was included or not. A mean score for the season was obtained for each patient, and these in turn were averaged to obtain the total symptom score for each treatment group.

Each patient was interviewed three times at 14-day intervals during the hay fever season by a physician who was not aware of the treatment received by the patient. At each interview the patient was asked to rate each symptom (sneezing, stuffy nose, rhinorrhea, and red, itchy eyes) as severe, moderate, slight, or none. The eyes were examined, and the severity of conjunctivitis was rated as none, slight, moderate, or severe. The nasal mucous membranes were examined for edema, change in color, and amount of secretion. The ratings for symptoms and physical signs were scored on a 0 to $3+$ scale, and those derived from the three visits were averaged to give a single seasonal score for each patient.

Pollen counts. Quantitative ragweed pollen counts were obtained from roto-slide samplers placed at several locations in the Baltimore area. ${ }^{4}$

Histamine release procedure. The methods used for the estimation of histamine release from washed leukocyte suspensions and for measurements of antigen-neutralizing capacity in sera from allergic donors have previously been described in detail $(11,13,14)$. They may be briefly summarized as follows: Blood was drawn by venipuncture, and the leukocytes were isolated, washed and suspended in a Tris-buffered solution containing optimal levels of calcium and magnesium, as well as $0.03 \%$ human serum albumin (Tris-ACM). The final concentration of leukocytes was $3.75 \times 10^{\circ}$ per $\mathrm{ml}$, as estimated with a model A Coulter counter.

Antigen. Antigen E (provided as Fraction IV) was stored in the frozen state as previously described (11).

Normal human serum (NHS). A pool of NHS from six donors, blood type $\mathrm{AB}$, was stored at $-20^{\circ} \mathrm{C}$ in samples sufficient for a single experiment. These donors had no history of ragweed allergy, and their leukocytes did not release histamine when challenged with high concentrations of antigen $\mathrm{E}(\geqslant 1.0 \mu \mathrm{g}$ per $\mathrm{ml})$. Serum from $A B$ donors was used to minimize cell-serum interaction, but in occasional instances, as noted earlier (13), histamine release was observed in tubes containing NHS

\footnotetext{
3 Courtesy of the Schering Corp., Bloomfield, N. J.

4 We are grateful to Dr. Marie B. Rhyne for furnishing the pollen counts.
} 


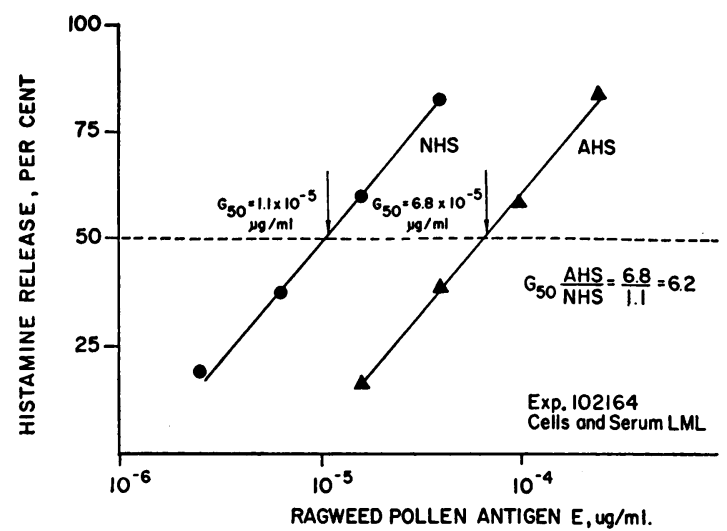

Fig. 1. DOSE-RESPONSE CURVES OF ONE INDIVIDUAL'S CELLS IN $10 \%$ NORMAL (NHS) AND AUTOLOGOUS ALLERGIC (AHS) HUMAN SERUM. The method of calculating the level of antibody, or the $\mathrm{G}_{\mathrm{B} 0}$ (AHS/NHS), is indicated.

but lacking ragweed antigen. When this "spontaneous" release exceeded $10 \%$, the experiment was discarded.

Allergic human serum $(A H S)$. Whenever blood was drawn for leukocyte isolation, an additional quantity was obtained to provide serum for antigen-neutralizing capacity titrations. The serum was removed within 2 hours after drawing the blood and was not heat inactivated. The antibody level was titrated on the day the serum was obtained.

Assay for antigen-neutralizing capacity. Since human serum from nonallergic donors may enhance the release of histamine, estimates of antigen-neutralizing capacity in AHS were always compared with a NHS control (14). Preliminary antigen dose-response curves were established for the cells of each donor so that subsequent titrations might be in the range of partial response. This was necessary because the dose response curves of different cell populations vary over a 10,000 -fold range (11). The use of inappropriately high levels of antigen may therefore provide data in the insensitive "plateau" region of the curve, or even in the region of inhibition due to antigen excess. Appropriate dilutions of ragweed antigen were mixed with samples of pooled NHS or autologous AHS, each at a final concentration of $10 \%$. After incubation for 60 minutes at either $25^{\circ}$ or $37^{\circ} \mathrm{C}$ (14), the antigen-serum mixtures were transferred to a $4^{\circ} \mathrm{C}$ bath. One $\mathrm{ml}$ of a standardized suspension of the patient's cells was then added to each reaction tube, which was incubated at $37^{\circ} \mathrm{C}$ for 60 minutes. The tubes were centrifuged and the supernates assayed for released histamine by a modification (11) of the fluorometric method of Shore, Burkhalter, and Cohn (21). A typical experiment, yielding two dose-response curves, is shown in Figure 1. The displacement of the line describing the AHS titration relative to that of the NHS titration provides a measure of the antibody activity in the allergic serum. The amount of antigen required for $50 \%$ histamine release in AHS divided by the amount necessary for the same percentage release in NHS yields the ratio, $G_{50}$ (AHS/NHS). This ratio describes the ability of the patient's serum to combine with ragweed antigen, thereby diminishing its capacity to release histamine from reactive leukocytes. The value, $\mathrm{G}_{50}$ (AHS/ NHS), therefore provides a measurement of the biologic, or antiallergic, activity of the patient's serum.

This assay resembles that of a virus neutralization reaction in that both reactions are carried out in the presence of a large excess of antibody, so that a constant percentage, rather than a constant quantity, of the added antigen is rendered unreactive. In the ragweed system this phenomenon is observed over the entire range of antigen concentrations utilized, that is, from $10^{-6}$ to $10^{-1}$ $\mu \mathrm{g}$ of protein per $\mathrm{ml}(14)$.

\section{Results}

\section{I) Titrations for antigen-neutralizing capacity}

A) Sera of untreated patients. Before initiating therapy we determined the level of antigen-neutralizing capacity (ANC) in 80 sera obtained from 32 patients who had never received parenteral injections of ragweed extract for diagnostic or therapeutic purposes. The results of these analyses are given in Figure 2. The sera of every untreated donor had antibody activity, with an average $\mathrm{G}_{50}(\mathrm{AHS} / \mathrm{NHS})$ value of $2.9 \pm \mathrm{SD} 1.3$. The lowest ratio observed was 1.3. For comparison, the sera of 13 randomly selected individuals who did not manifest clinical allergy were tested against the reference NHS. The average $\mathrm{G}_{50^{-}}$ (AHS/NHS) was $0.98 \pm \mathrm{SD} 0.16$. The highest

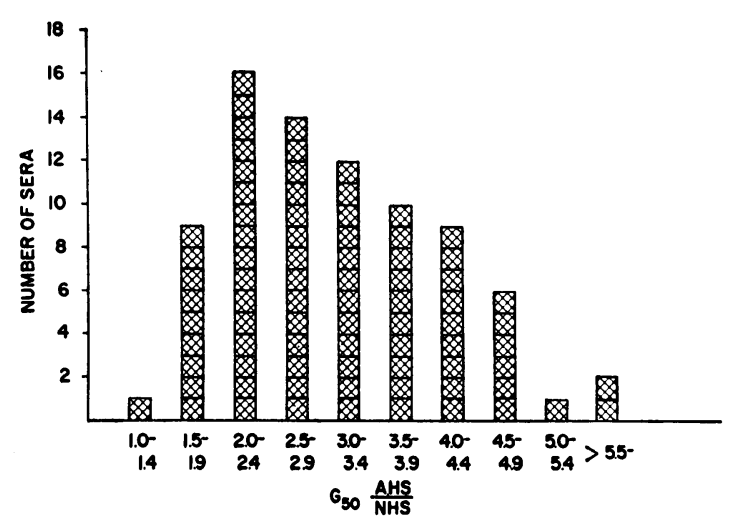

Fig. 2. Distribution of antigen-NeUtralizing CAPACITY IN 80 SERA OBTAINED FROM 32 UNTREATED, RAGWEED-SENSITIVE DONORS. Each box represents the value for one serum expressed as $\mathrm{G}_{\mathrm{B} 0}$ (AHS/NHS), i.e., the ratio of antigen required for 50 histamine release in the presence of AHS and NHS. The same normal serum pool was used for all reference determinations. The allergic serum and the leukocytes were always taken from the same donor. 
TABLE I

Average antigen-neutralizing capacity ot the groups treated with placebo and crude ragweed extract

\begin{tabular}{|c|c|c|c|c|c|}
\hline \multirow[b]{2}{*}{ Month } & $\begin{array}{c}\mathrm{G}_{50} \\
\text { (AHS/ } \\
\text { NHS)* }\end{array}$ & $\begin{array}{c}\text { No. } \\
\text { pa- } \\
\text { tients }\end{array}$ & $\begin{array}{c}\mathrm{G}_{50} \\
\text { (AHS/ } \\
\text { NHS) }\end{array}$ & $\begin{array}{c}\text { No. } \\
\text { pa- } \\
\text { tients }\end{array}$ & \multirow[b]{2}{*}{$\begin{array}{l}t \text { test of } \\
\text { difference }\end{array}$} \\
\hline & \multicolumn{2}{|c|}{$\begin{array}{l}\text { Placebo-treated } \\
\text { group }\end{array}$} & \multicolumn{2}{|c|}{$\begin{array}{l}\text { Crude ragweed- } \\
\text { treated group }\end{array}$} & \\
\hline April & $3.1 \pm 0.9$ & 9 & $3.2 \pm 1.2$ & 12 & NS \\
\hline May & $3.1 \pm 0.9$ & 13 & $3.6 \pm 1.3$ & 9 & NS \\
\hline June-July & $3.2 \pm 1.0$ & 15 & $4.7 \pm 2.4$ & 12 & $\mathrm{p}<0.05$ \\
\hline August-September & $2.6 \pm 0.9$ & 12 & $8.3 \pm 4.7$ & 13 & $\mathrm{p}<0.001$ \\
\hline October-December & $2.8 \pm 1.1$ & 9 & $6.2 \pm 4.4$ & 18 & $p=0.02$ \\
\hline
\end{tabular}

* Go $($ AHS/NHS) $=$ the ratio of antigen required for $50 \%$ histamine release in the presence of allergic human serum and normal human serum.

ratio observed in this normal group was 1.25 , indicating that, within experimental error, there was no antigen binding by these normal sera. In contrast, the sera of all ragweed-sensitive patients tested thus far exhibit ragweed-neutralizing activity.

B) Sera of placebo-treated patients. The antibody activity levels in the sera of patients in the placebo and crude ragweed extract groups, both previously untreated, were similar before therapy (Table I). The $\mathrm{G}_{50}(\mathrm{AHS} / \mathrm{NHS}$ ) values for the placebo group were essentially constant throughout the period of study, with a tendency towards a slight decline during the last 4 months (Table I, Figure 3, solid circles).

C) Sera of patients treated with crude ragweed extracts. These sera showed a moderate increase in ANC for antigen E (Table I, Figure 3). The average values rose from 3.2 before treatment to 8.3 (Table I), and the sera of two individuals exceeded a value of 10 (Figure 3 ). This modest response may reflect the fact that only small quantities of antigen $\mathrm{E}$ are present in crude extracts. Although the patients received 0.39 to $28.8 \mu \mathrm{g}$ protein $\mathrm{N}$ of the crude extract, the amount of antigen $\mathrm{E}$ contained therein was but 0.15 to $11 \mu \mathrm{g}$ protein $(0.026$ to $1.84 \mu \mathrm{g}$ protein $\mathrm{N})$. All the ANC assays were carried out with antigen $E$ so that antibodies to the remaining antigenic constituents of ragweed would not have been detected. There was no apparent correlation between the quantity of antigen administered and the maximal serum antibody levels. Only half of the group, however, manifested a rise in antibody levels greater than those in the sera from nontreated allergic donors.

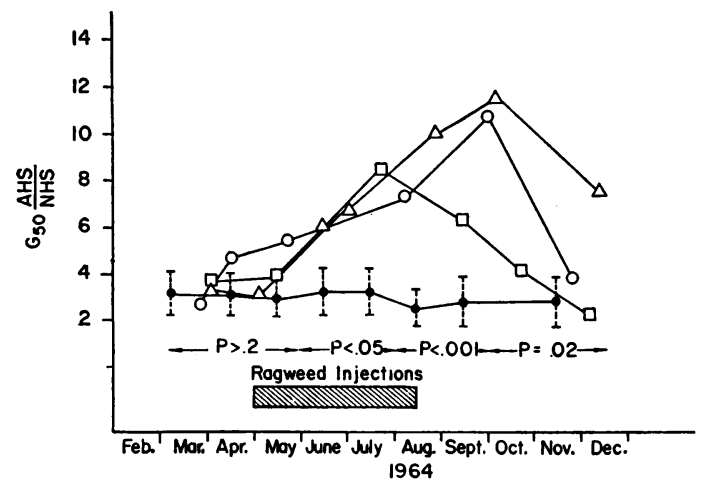

Fig. 3. The antibody Response of three patients (OPEN SYMBOLS) TREATED WITH COMMERCIAL RAGWEED EXTRACT CONTRASTED WITH THE AVERAGE RESPONSE ( \pm 1 SD) FOR THE GROUP RECEIVING PLACEBO INJECTIONS (SOLID CIRCLES). The three patients illustrated above manifested the highest antibody levels in the group. The $\mathrm{p}$ values indicate the significance of the difference between the placebo- and ragweed-treated groups, as a whole, for the periods indicated.

D) Sera of patients treated with antigen $E$. These sera were first titrated in March and April of 1964. During the previous year, from May until August the patients in this group received a

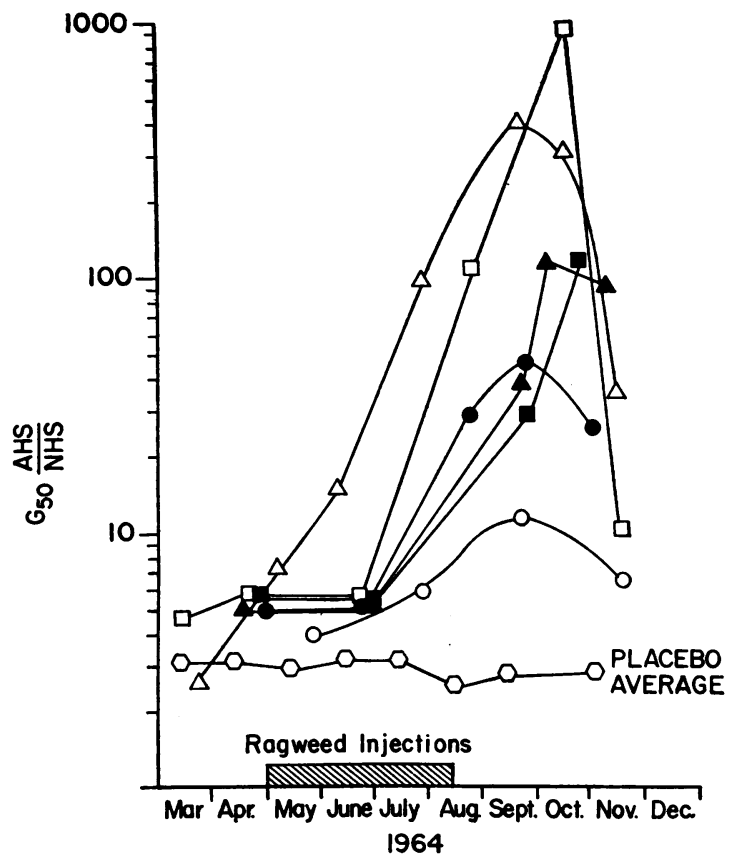

Fig. 4. The antibody Response of Six patients TREATED WITH RAGWEED ANTIGEN E CONTRASTED WITH THE AVERAGE RESPONSE OF A GROUP RECEIVING ONLY PLACEBO INJECTIONS. The six patients illustrated here represent the entire range of response. 
TABLE II

Correlation between quantity of ragweed antigen $E$ administered and the maximal observed antibody response*

\begin{tabular}{lcccc}
\hline \hline & $\begin{array}{c}\text { Antigen E } \\
\text { Patient } \\
\text { administered }\end{array}$ & $\begin{array}{c}\text { Rank order } \\
\text { in terms of } \\
\text { antigenic } \\
\text { mass }\end{array}$ & $\begin{array}{c}\text { Maximal } \\
\text { Gso } \\
\text { (AHS/NHS) } \\
\text { observed }\end{array}$ & $\begin{array}{c}\text { Rank order } \\
\text { in terms of } \\
\text { maximal } \\
\text { antibody } \\
\text { response }\end{array}$ \\
\hline & $\mu g$ & & & \\
$\mathrm{Ne}$ & 62 & 1 & 1,000 & 1 \\
$\mathrm{El}$ & 46 & 2 & 125 & 3 \\
$\mathrm{Yo}$ & 43 & 4 & 100 & 5 \\
$\mathrm{Jo}$ & 43 & 4 & 420 & 2 \\
$\mathrm{Ki}$ & 43 & 4 & 47 & 6 \\
$\mathrm{St}$ & 36 & 6 & 33 & 7 \\
$\mathrm{Wy}$ & 28 & 7 & 13 & 8 \\
$\mathrm{Ke}$ & 24 & 8 & 120 & 4 \\
$\mathrm{Pu}$ & 16 & 9 & 12 & 9 \\
$\mathrm{Ri}$ & 4 & 10 & 11 & 10 \\
\hline
\end{tabular}

* Spearman rank correlation coefficient $=0.830 ; \mathrm{p}$ $<0.01$.

series of 15 weekly injections comprising a total dose of 3.7 to $6.4 \mu \mathrm{g}$ of antigen $\mathrm{E}$. The average $\mathrm{G}_{50}$ (AHS/NHS) value was $4.7 \pm \mathrm{SD} 1.9$. The antibody levels in these sera were therefore significantly higher $(p<0.01)$ than those of the control group $\left[\mathrm{G}_{50}(\mathrm{AHS} / \mathrm{NHS})=2.9 \pm \mathrm{SD}\right.$ 1.3] at the outset of the present study.

During the subsequent period of treatment, in 1964, the sera of all individuals treated with antigen $\mathrm{E}$ developed increased antigen-neutralizing activity. The results of successive titrations with the sera of six individuals representing the entire range of results are plotted in Figure 4. The pattern of response in these individuals differs from that of subjects treated with crude extract mainly with respect to the magnitude of the antigen-neutralizing activity (cf. Figure 3). A logarithmic ordinate was used in Figure 4 to include the entire range of $\mathrm{G}_{50}(\mathrm{AHS} / \mathrm{NHS})$ values. The rise in antibody activity occurred from May to September. When desensitization was discontinued in August, the neutralizing activity in all sera continued to rise for a month or two, and then fell rather rapidly, as was also noted in the crude ragweed group.

The data compiled in Table II show that there was a significant correlation between the magnitude of the immunizing dose and the maximal antibody level $(\mathrm{p}<0.01)$.

II) Changes in cell sensitivity after therapeutic immunization

Before the onset of desensitization therapy the cell sensitivities of the three treatment groups were quite similar. The median value and range of the antigen concentrations required for $50 \%$ histamine release in NHS were $48 \times 10^{-6}$ ( 9 to 500 $\left.\times 10^{-6}\right), 28 \times 10^{-6}\left(5\right.$ to $\left.600 \times 10^{-6}\right)$, and $56 \times$ $10^{-6}\left(5\right.$ to $\left.320 \times 10^{-6}\right) \mu \mathrm{g}$ per $\mathrm{ml}$, for the placebo-, antigen E-, and crude ragweed-treated groups, respectively.

The change in leukocyte reactivity for each subject as a consequence of specific therapy is depicted in Figure 5. Each point in the graph represents the logarithm of the ratio between the mean cell sensitivity obtained in two assays before the onset of therapy and that found in two titrations performed during and immediately after the ragweed season, i.e., at the conclusion of therapy. The quantity of antigen required for $50 \%$ histamine release increased in six of the eleven subjects in the placebo group (e.g., the cells became less sensitive) and decreased in five. Thus, for the group as a whole there was little change in the amount of antigen required to yield a $50 \%$ response, the average value of the ratios before and after the ragweed season being $0.041 \pm 0.35$. The results for the crude ragweed group as a whole are quite similar. In the antigen E-treated group, on the other hand, the leukocytes of nine individuals required more antigen after treatment, whereas in only two was less antigen required.

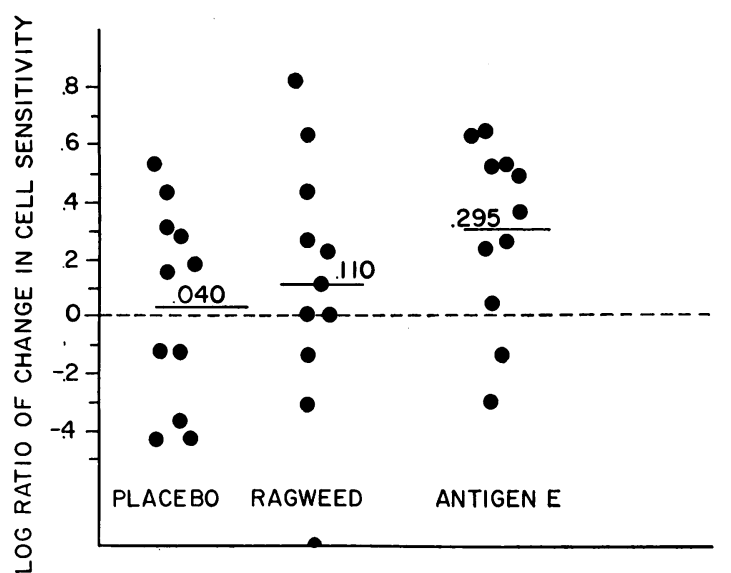

Fig. 5. The change in in vitro leukocyte SensiTIVITY FOR THREE GROUPS OF PATIENTS TREATED AS INDICATED. Each circle represents one patient; the solid lines indicate the group average. The change in cell sensitivity is judged by the $\log$ of the ratio between the $G_{50}$ NHS before, and during and immediately after the ragweed season. Student's $t$ test indicates that the difference between the placebo and antigen $E$ groups is $0.1>\mathrm{p}>0.05$. 
The average ratio was $0.29 \pm 0.31$, indicating a mean increase of $100 \%$ in the amount of antigen required for $50 \%$ histamine release. An analysis of the difference between the placebo and the antigen E-treated groups by Student's $t$ test shows that $0.1>p>0.05$.

In no instance were the changes described above associated with a diminution in the ability of the cells to release histamine. Eighty to $100 \%$ histamine release was obtained repeatedly with an optimal antigen concentration, even in the presence of AHS, and at the height of the antibody response. Not all cell suspensions from allergic donors can release $100 \%$ of their histamine, since 10 to $20 \%$ of the population reach plateau values at less than $50 \%$ histamine release (11). Such individuals were not included in this study.

\section{III) Clinical results}

The severity of the clinical illness, as measured by the average daily symptom score, correlated well with natural exposure to pollen as measured by quantitative ragweed pollen counts (Figure 6). Symptoms tended to be somewhat greater in relation to the pollen count late in the ragweed season, an observation made previously with respect to daily symptom evaluation (17).

The average daily symptom scores for the entire ragweed season were slightly lower for the two treated groups than for the placebo group (Table III), the differences being due largely to the divergence in scores during the height of pollen exposure (Figure 6). Physician evaluation scores showed the same trend (Table III).

The numbers designating the symptom score averages cannot be considered exact in any numerical sense, but simply facilitate the listing of patients in a rank order relationship of decreasing allergic disease symptoms. These rank order re-

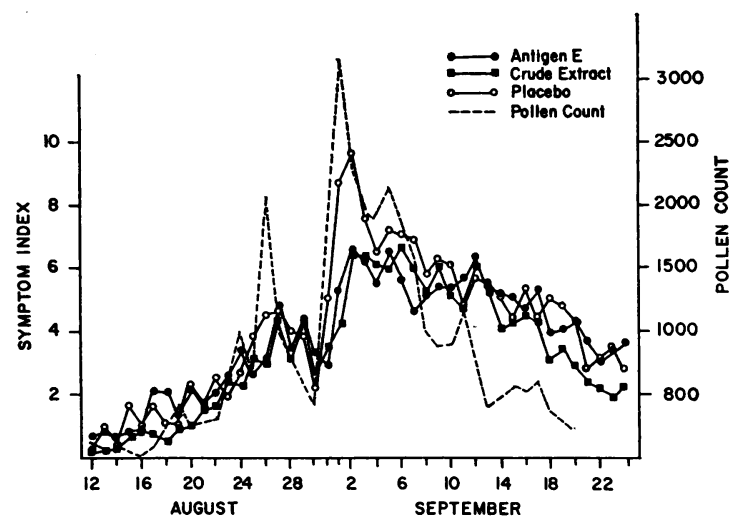

Fig. 6. COMPARISON BETWEEN AVERAGE SYMPTOM SCORES OF THREE GROUPS OF RAGWEED-SENSITIVE PATIENTS AND QUANTITATIVE POLLEN COUNTS.

lationships were treated statistically by "nonparametric" methods, which require no assumptions regarding the normal distribution of the data or their equality of variance. Although the two specific treatment groups reported slightly milder symptoms than untreated controls, the differences did not meet these tests of significance. Likewise, the difference between the treated and control groups noted in the physician scores was not significant. Application of the Mann Whitney U test (22) to these data gave $p$ values that were 0.05 or greater.

A high degree of correlation was noted between the rank of symptom severity as determined by the patients' diaries and by physician evaluation. Moreover, patients who received the more complete schedule of inoculations reported fewer symptoms than those who received less antigen. This might be expected, since the quantity of antigen administered was limited by the tendency of the patient to have local or systemic reactions to the antigen. Calculation of the Spearman rank correlation coefficient showed that this relationship

TABLE III

Antigen dosage and symptom scores of the three treatment groups

\begin{tabular}{|c|c|c|c|c|c|c|c|}
\hline & \multirow{2}{*}{$\begin{array}{l}\text { No. } \\
\text { patients }\end{array}$} & \multicolumn{2}{|c|}{ Total dose } & \multicolumn{2}{|c|}{$\begin{array}{l}\text { Patient's symptom } \\
\text { score }\end{array}$} & \multicolumn{2}{|c|}{$\begin{array}{l}\text { Physician's symptom } \\
\text { score }\end{array}$} \\
\hline & & Average & Range & $\overline{\text { Average }}$ & Range & Average & Range \\
\hline Controls & 12 & 0.0 & & 3.7 & $0.3-11.8$ & 11.0 & $1.3-27.3$ \\
\hline Crude extract & 12 & $8.8 \mu \mathrm{g}$ protein $\mathrm{N}$ & $0.3-28.8 \mu \mathrm{g}$ protein $\mathrm{N}$ & 3.0 & $0.9-6.5$ & 9.6 & $4.7-17.0$ \\
\hline Antigen $\mathrm{E}$ & 10 & $\begin{array}{l}34.8 \mu \mathrm{g} \text { protein } \\
(5.9 \mu \mathrm{g} \text { protein } \mathrm{N})\end{array}$ & $\begin{array}{l}4.0-61.7 \mu \mathrm{g} \text { protein } \\
(0.7-11.2 \mu \mathrm{g} \text { protein } \mathrm{N})\end{array}$ & 3.4 & $1.1-7.3$ & 8.6 & $5.0-14.3$ \\
\hline
\end{tabular}


was significant in patients receiving whole ragweed extract $(0.05>\mathrm{p}>0.01)$. A similar trend was noted in patients receiving antigen $\mathrm{E}$, but the correlation was not considered significant.

The observation that patients who received specific therapy showed little symptomatic improvement may be due to inherent limitations in the desensitization procedure. However, others have observed that the first year of therapy affords little benefit, and improvement comes only after 2 or even 3 years of treatment (23). In addition, the amounts of crude extract employed in this study were smaller than those that yielded successful results in two other controlled clinical studies $(23,24)$, although they were similar to those used in the allergy clinic of this institution. The dose of antigen $\mathrm{E}$ that might be required to produce a good therapeutic result is still unknown. However, a few of the patients receiving antigen $\mathrm{E}$ may have experienced clinical improvement, as discussed below.

\section{IV) Laboratory-clinical correlations}

The failure to find significant differences in the clinical status of the placebo group as compared to the two immunized groups obviously limits the possible correlations between laboratory results and the effects of treatment. A significant relationship did, however, emerge in comparisons of the in vitro reactivity of a patient's cells to antigen $\mathrm{E}$ and the severity of his symptoms. Figure 7 links the cell sensitivity, i.e., the $\mathrm{G}_{50} \mathrm{NHS}$, determined before the ragweed season, with the symptom scores as evaluated by the patient (left) and by the physician (right), for the 24 patients of the placebo- and crude ragweed-treated groups. Those individuals whose cells were most sensitive (i.e., their cells required the least antigen for $50 \%$ histamine release) generally experienced the most severe symptoms. The Spearman rank correlation coefficient between cell sensitivity and severity of symptoms was higher $(0.77)$ in terms of the patients' daily scores than in terms of the physician's scores (0.59). Both methods of evaluation provide a statistically significant correlation $(p<0.01)$. Since relatively small changes in individual cell sensitivity were observed over the period of this study (Figure 5), as compared to the range of cell sensitivities shown in Figure 7, these correlations would obtain throughout the en- tire period of study. Those cell sensitivities determined before the ragweed season are reported in Figure 7 to illustrate the prognostic utility of this correlation.

When the placebo- and the crude ragweedtreated groups were considered separately, the correlation between cell sensitivity and symptom scores, as judged by either the patient or the doctor, was still significant. Each of the four correlations was at the $p<0.05$ to 0.01 level. It follows therefore that an assay of cell sensitivity in an untreated individual has predictive value for the relative severity of hay fever symptoms likely to be experienced during the season of ragweed pollination.

For the group treated with antigen $\mathrm{E}$, in contradistinction to the two other groups, the cell sensitivity did not predict the observed symptomatology. In this group were found the sera that showed the highest antigen-neutralizing activities, and it appears that the antibody level may have influenced the intensity of symptoms. This possibility is considered in Table IV, which lists the cell sensitivity of the donors in this group and, employing this value, an expected symptom score interpolated from Figure 7 (patient evaluation). Also recorded is the patient's maximal antibody level and, finally, his actual symptom score. It can be seen that in three patients the symptom scores expected from the cell sensitivity levels were attained ( $\mathrm{Ri}, \mathrm{Wy}$, and $\mathrm{St}$ ), and each of these donors developed only a minimal rise in antibody level $\left[\mathrm{G}_{50}(\mathrm{AHS} / \mathrm{NHS})=11,13\right.$, and 33 , respectively]. On the other hand, five patients had fewer symptoms than expected ( $\mathrm{El}, \mathrm{Ke}, \mathrm{Ki}, \mathrm{Ne}$, Yo), and these donors had the highest levels of antibody $\left[\mathrm{G}_{50}(\mathrm{AHS} / \mathrm{NHS})=125,120,47,1,000\right.$, 100 , respectively]. The remaining two donors had relatively insensitive cells and experienced more severe symptoms than predicted by their cell sensitivity. These results are compatible with the suggestion that high levels of circulating antianaphylactic antibody can influence the clinical response of allergic donors, but it will be necessary to study a greater number of patients before this hypothesis is confirmed.

\section{Discussion}

This investigation was planned to evaluate in vitro studies of human allergy in a carefully con- 


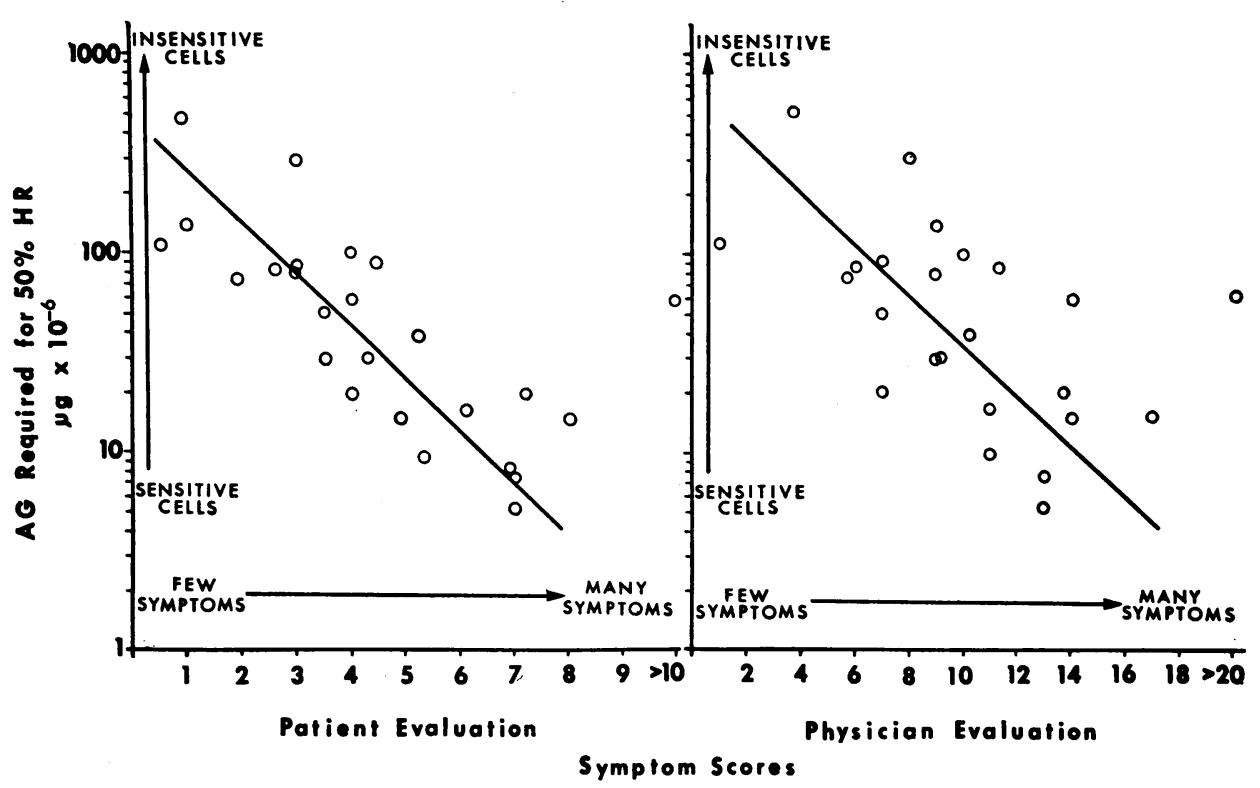

Fig. 7. The Relation BetWeen IN vitro Leukocyte SENSitivity AS JUdGed by duplicate TITRATIONS PERFORMED IN MARCH AND APRIL 1964 AND THE SYMPTOMS THESE INDIVIDUALS SUFFERED DURING THE RAGWEED SEASON OF THE SAME YEAR. The patients evaluated their symptoms twice daily; the physician's evaluation is based on three visits during the ragweed season. Spearman rank correlation coefficient for patient evaluation $=0.765 \mathrm{p}<0.01$; Spearman rank correlation coefficient for physician evaluation $=0.592 \mathrm{p}<0.01$. AG $=$ antigen; HR $=$ histamine release.

trolled clinical situation involving desensitization therapy. We have studied the relationship between three different parameters: 1) the sensitivity of a donor's cells to the inciting antigen; 2) the level of antibody reactive with this antigen, as detected by its capacity to inhibit the allergic response; and 3 ) the intensity of the symptomatology manifested by the patient during the season of environmental exposure to the antigen. In each instance the response of patients under immunization with the offending antigen has been compared with that of controls who received only placebo injections.

We showed earlier that allergic patients differ markedly in the quantity of antigen required for a $50 \%$ release of histamine (11). It may now be concluded that this in vitro measurement of sensitivity to specific antigen is closely correlated with the frequency and intensity of symptoms experienced by the cell donor (Figure 7). This correlation attests to the validity of the present in vitro procedure as an experimental reaction system. Measurements of skin-sensitizing antibody (25) have also been shown to provide an index of pa- tient symptomatology, but this procedure is a less precise prognostic tool than are the cell sensitivity studies reported here. Direct skin testing, on the other hand, has not been considered a useful index of the severity of the clinical condition $(26,27)$.

The changes in cell sensitivity that resulted from treatment or from environmental exposure to ragweed antigen were quantitatively unimpressive, as the maximal change was less than ten-

TABLE IV

Cell sensitivity, antigen-neutralizing capacity, and expected and actual symptom scores for the group treated with antigen $E$

\begin{tabular}{|c|c|c|c|c|}
\hline Patient & $\begin{array}{c}\text { Cell } \\
\text { sensitivity } \\
\text { G }_{50} \mathrm{NHS} \\
\times 10^{-6} \mu \mathrm{g}\end{array}$ & $\begin{array}{c}\underset{\text { Maximal }}{\text { Mat }} \\
\text { (AHS/ } \\
\text { NHS) }\end{array}$ & $\begin{array}{l}\text { Expected } \\
\text { symptoms }\end{array}$ & $\begin{array}{c}\text { Actual } \\
\text { symptoms }\end{array}$ \\
\hline El & 4.5 & 125 & 7.7 & 3.3 \\
\hline $\mathbf{R i}$ & 6.0 & 11 & 7.3 & 8.0 \\
\hline Wy & 13 & 13 & 6.0 & 5.8 \\
\hline $\mathrm{Ke}$ & 15 & 120 & 5.7 & 4.8 \\
\hline $\mathrm{Ki}$ & 16 & 47 & 5.6 & 3.8 \\
\hline $\mathrm{Ne}$ & 28 & 1,000 & 4.8 & 2.9 \\
\hline Yo & 47 & 100 & 4.0 & 1.7 \\
\hline St & 70 & 33 & 3.5 & 4.0 \\
\hline Jo & 260 & 420 & 1.5 & 7.6 \\
\hline $\mathbf{P u}$ & 600 & 12 & 0.5 & 2.6 \\
\hline
\end{tabular}


fold. In terms of group averages, the values for the placebo group were essentially unchanged. The leukocytes from patients treated with antigen $\mathrm{E}$, however, required more antigen to release $50 \%$ of the cellular histamine during the ragweed season, as compared to the pretreatment period; this difference was not statistically significant. Our findings are at variance with those in two recent and preliminary reports, which indicate that the cells of some allergic individuals no longer respond fully to an antigenic stimulus after a prolonged and intensive course of immunization (28, 29). It has been suggested that the cells of these donors had become refractory, i.e., the cells were no longer capable of a maximal histamine release, regardless of the antigen level. We did not observe results of this nature. The slight decrease in cell sensitivity that we noted signifies only that an increased quantity of antigen was required to achieve the same level of response. Our failure to observe the development of a refractory state may be due to the smaller quantities of antigen used in these, as compared to the other studies. We can, however, report one donor, studied for other purposes, whose cells spontaneously became refractory. Dose-response curves obtained with the cells of this subject, on a dozen occasions over 18 months, all showed more than $80 \%$ histamine release. Two years later this patient, who had received no therapy in the interim, reported that his symptoms had virtually disappeared. Titration of his cells at this time showed that only $20 \%$ of the cellular histamine could be released at optimal antigen concentrations, with higher antigen levels causing inhibition.

The sera of all ragweed-sensitive patients, including those of untreated individuals, contain allergen-binding antibodies, as shown by the data in Figure 2. The level of this antibody activity did not change significantly as a result of environmental exposure to antigen during the ragweed season, but did increase after immunization ( $\mathrm{Ta}$ bles I and II, Figures 3 and 4). The increase was moderate in the group treated with crude ragweed, and in about half of these subjects the antibody levels were no higher than $1 \mathrm{SD}$ above the average for the untreated group. As noted above, the inoculum for these individuals contained many ragweed pollen antigens, whereas only one was used in estimating the antibody response. In contrast, all individuals treated with antigen $\mathrm{E}$ responded with an increased level of antibody activity (Table II, Figure 4). The increase varied from 3- to 300fold in different individuals and was significantly correlated with the quantity of antigen administered.

Parenteral immunization with pollen antigens is known to stimulate the production of "blocking antibodies" (6), which bind antigen but do not mediate passive sensitization. A deficiency in the latter property suggests that these antibodies also have a lower affinity for the leukocyte surface than do the classic "reagins," and hence would not displace them from the cell. The relationship between our measurements of antigen-neutralizing capacity and so-called blocking antibodies is not yet clear. However, the presence in the serum of antigen neutralization activity, even at elevated levels, is compatible with the minimal changes noted in the sensitivity of the isolated leukocytes. The effect of serum antibody levels greater than those we observed remains to be explored.

The method used for estimating the antigen-neutralizing capacity in sera of allergic donors is perhaps uniquely suitable for the present study. This procedure provides a quantitative measure of the biologic activity of the antibody, i.e., its capacity to unite with antigen and inhibit the allergic response (14). The correlation between cell sensitivity and patient symptomatology that emerged in the present investigation shows that cell sensitivity may be used as a reference against which to evaluate the clinical efficacy of any increase in antibody activity.

From the data presented above it appears likely that the goal of therapy should be to decrease the effective sensitivity of the histamine-releasing cells in their milieu of extracellular fluid. This may be achieved by at least two mechanisms. The cellular sensitivity itself, attributable to cell-bound antibodies, may be reduced. The changes that we have noted in this respect have thus far been too small to influence clinical symptoms. More intensive immunization might be more effective in altering cell sensitivity, as is suggested by the preliminary reports of others $(28,29)$. The other pertinent mechanism involves increased serum antibody levels. Our data suggest that in several individuals treated with antigen $\mathrm{E}$ the immune 
response sufficed to influence the clinical course, i.e., these patients had fewer symptoms than were anticipated on the basis of their cell sensitivity. It appears likely, therefore, that some combination of cell sensitivity and antigen-neutralizing capacity is the principal determinant of clinical symptomatology in ragweed pollinosis.

\section{Summary}

An in vitro reaction system for the study of human allergy has been utilized to evaluate the effects of desensitization therapy in ragweed pollinosis. This system involves the antigenically induced release of histamine from isolated human leukocytes and is designed to allow an independent evaluation of cellular and humoral factors. The sensitivity of a donor's leukocytes to the offending antigen correlated significantly with the degree of symptomatology suffered by that patient during the ragweed season. The cell sensitivity was not altered by environmental exposure to this antigen or by the therapeutic regimen used in this study. The sera of all ragweed-sensitive patients, whether treated or not, contained antibodies capable of binding the antigen and thereby decreasing the in vitro allergic response. The level of antibody activity did not change in a group of patients receiving placebo immunization, but did increase in the groups treated with ragweed antigen. The extent of this response correlated well with the quantity of antigen $\mathrm{E}$ administered. Although there was no significant clinical difference between the groups treated with placebo and specific antigen, it appears that several individuals whose sera developed the highest levels of antiragweed activity had milder symptoms than expected on the basis of their cellular sensitivity to antigen.

\section{Acknowledgments}

The statistical analysis of the data in this paper was suggested by Dr. Earl Diamond. The authors are extremely grateful for his help, as well as the technical assistance of Mrs. JoAnne Tignall.

\section{References}

1. Noon, L. Prophylactic inoculation against hay fever. Lancet 1911, 1, 1572.

2. Tuft, L., and G. I. Blumstein. Pollen tolerance nasal tests in hay fever. Experimental and clinical observations. J. Allergy 1950, 21, 326.
3. Feinberg, S. M., R. A. Stier, and W. C. Grater. A suggested quantitative evaluation of the degree of sensitivity of patients with ragweed pollinosis. J. Allergy 1952, 23, 387.

4. Baldwin, L. B., and J. Glaser. Effect of treatment on skin and mucous membrane sensitivity and on reagins in hay fever. J. Allergy 1936-37, 8, 129.

5. Sherman, W. B., A. Stull, and R. A. Cooke. Serologic changes in hay fever cases treated over a period of years. J. Allergy 1940, 11, 225.

6. Loveless, M. H. Immunological studies of pollinosis : I. The presence of two antibodies related to the same pollen-antigen in the serum of treated hayfever patients. J. Immunol. 1940, 38, 25.

7. Gordon, J., B. Rose, and A. H. Sehon. Detection of "non-precipitating" antibodies in sera of individuals allergic to ragweed pollen by an in vitro method. J. exp. Med. 1958, 108, 37.

8. Connell, J. T., and W. B. Sherman. Skin sensitizing antibody titer. III. Relationship of the skin-sensitizing antibody titer to the intracutaneous skin test, to the tolerance of injections of antigens, and to the effects of prolonged treatment with antigen. J. Allergy 1964, 35, 169.

9. Loveless, M. H. Immunological studies in pollinosis. IV. The relationship between thermostable antibody in the circulation and clinical immunity. J. Immunol. 1943, 47, 165.

10. Arbesman, C. E., S. Z. Kantor, D. Rapp, and N. R. Rose. Immunologic studies of ragweed-sensitive patients. III. Clinical aspects: the relationship of reagin and hemagglutinating antibody titers to results of hyposensitization therapy. J. Allergy 1960, 31, 342.

11. Lichtenstein, L. M., and A. G. Osler. Studies on the mechanisms of hypersensitivity phenomena. IX. Histamine release from human leukocytes by ragweed pollen antigen. J. exp. Med. 1964, 120, 507.

12. Osler, A. G., L. M. Lichtenstein, and D. A. Levy. Immunologic aspects of human reaginic allergy: an in vitro method and some applications. NaunynSchmiedeberg's Arch. exp. Path. Pharmak. 1965, 250, 111.

13. Lichtenstein, L. M., and A. G. Osler. Studies on the mechanisms of hypersensitivity phenomena. XI. The effect of normal human serum on the release of histamine from human leukocytes by ragweed pollen antigen. J. Immunol. 1966, 96, 159.

14. Lichtenstein, L. M., and A. G. Osler. Studies on the mechanisms of hypersensitivity phenomena. XII. An in vitro study of the reaction between ragweed pollen antigen, allergic human serum and ragweed-sensitive human leukocytes. J. Immunol. 1966, 96, 169.

15. VanArsdel, P. P., Jr., and E. Middleton, Jr. The effect of hyposensitization on the in vitro histamine release by specific antigen. J. Allergy 1961, 32, 348. 
16. Spain, W. C., M. B. Strauss, and E. Neumann. In vitro release of histamine by hypersensitive (allergic) serum in contrast to immune (treated) allergic serum in antigen and normal rabbit blood mixtures. J. Allergy 1950, 21, 318.

17. Norman, P. S., and W. L. Winkenwerder. Suppression of hay fever symptoms with intranasal dexamethasone aerosol. J. Allergy 1965, 36, 284.

18. King, T. P., and P. S. Norman. Isolation studies of allergens from ragweed pollen. Biochemistry 1962, 1, 709.

19. King, T. P., P. S. Norman, and J. T. Connell. Isolation and characterization of allergens from ragweed pollen. II. Biochemistry 1964, 3, 458.

20. King, T. P. Personal communication.

21. Shore, P. A., A. Burkhalter, and V. H. Cohn, Jr. A method for the fluorometric assay of histamine in tissues. J. Pharmacol. exp. Ther. 1959, 127, 182.

22. Siegel, S. Nonparametric Statistics for the Behavioral Sciences. New York, McGraw-Hill, 1956.

23. Lowell, F. C., and W. Franklin. A "double-blind" study of treatment with aqueous allergenic ex- tracts in cases of allergic rhinitis. J. Allergy 1963, 34, 165.

24. Johnstone, D. E. Study of the role of antigen dosage in the treatment of pollenosis and pollen asthma. Amer. J. Dis. Child. 1957, 94, 1.

25. Connell, J. T., and W. B. Sherman. Skin sensitizing antibody. II. Relationship of hay fever symptoms to the skin sensitizing antibody titer in patients treated with ragweed emulsion injections, aqueous ragweed injections, or no injection treatment. J. Allergy 1964, 35, 18.

26. Criep, L. H. Clinical Immunology and Allergy. New York and London, Grune \& Stratton, 1962, p. 157.

27. Sherman, W. B., and W. R. Kessler. Allergy in Pediatric Practice. St. Louis, C. V. Mosby, 1957, p. 124.

28. Pruzansky, J. J., R. G. Slavin, and R. Patterson. Histamine release and ragweed binding in allergic subjects (abstract). J. Allergy 1965, 36, 196.

29. VanArsdel, P. P., Jr. Effect of specific hyposensitization on antigenic histamine release from human leukocytes. Fed. Proc. 1965, 24, 632. 